\title{
Prediction of Dermal Permeability Coefficient of Nevirapine-Effect of Cosolvents, Anionic, Nonionic and Cationic Surfactants
}

\author{
Chika J. Mbah ${ }^{*}$, Theophilus C. Onyekaba ${ }^{2}$, Agatha 0. Uwakwe1 \\ ${ }^{1}$ Department of Pharmaceutical and Medicinal Chemistry, Faculty of Pharmaceutical Sciences, \\ University of Nigeria, Nsukka, Nigeria \\ ${ }^{2}$ Department of Pharmaceutical Chemistry, Faculty of Pharmaceutical Sciences, \\ Delta State University, Abraka, Nigeria \\ Email: *cjmbah123@yahoo.com
}

Received 18 June 2016; accepted 25 July 2016; published 28 July 2016

Copyright (C) 2016 by authors and Scientific Research Publishing Inc.

This work is licensed under the Creative Commons Attribution International License (CC BY). http://creativecommons.org/licenses/by/4.0/

c) (i) Open Access

\section{Abstract}

Transdermal drug delivery not only has contributed immensely to medical practice, but has enjoyed enormous interest in the field of cosmetic and pharmaceutical industries. Nevirapine, a non-nucleoside reverse transcriptase inhibitor (NNRTI) is used clinically for the treatment of HIV1 infection. The aim of the present study is to investigate the influence of cosolvents (glycerol, propylene glycol, ethanol, polyethylene glycol 400) and surfactants (polysorbate 20, polysorbate 80, sodium lauryl sulfate, sodium cholate and cetrimide) on the dermal permeability coefficient of nevirapine by utilizing established and recognized mathematical model that employs partition coefficient as one of its molecular descriptors. The partition coefficient of nevirapine is determined in chloroform-water system at room temperature using the shake flask method. The results show that all the cosolvents used in this study decrease the partition coefficient of nevirapine. The same decrease in the partition coefficient of nevirapine is observed with all the surfactants investigated. The order of dermal enhancement potential of the vehicles studied based on the predicted permeability coefficient is glycerol > propylene glycol > ethanol > polyethylene glycol 400 for the cosolvents while tween $\mathbf{2 0}>$ tween $\mathbf{8 0}>$ sodium lauryl sulfate $>$ sodium cholate $>$ cetrimide for the surfactants. The maximum predicted flux through skin was obtained by multiplying the predicted permeability coefficient and the drug aqueous solubility. As the rate of penetration into the skin is quantitatively assessed by the use of permeability coefficient, the findings suggest that for dermal formulation of nevirapine, glycerol and tween 20 are the most preferred vehicles out of the ve-

${ }^{*}$ Corresponding author.

How to cite this paper: Mbah, C.J., Onyekaba, T.C. and Uwakwe, A.O. (2016) Prediction of Dermal Permeability Coefficient of Nevirapine-Effect of Cosolvents, Anionic, Nonionic and Cationic Surfactants. Pharmacology \& Pharmacy, 7, $283-289$. 
hicles investigated. Furthermore, the results of the correlation coefficients obtained by plotting permeability coefficient or maximum predicted flux, versus logarithm partition coefficient indicate that permeability coefficient can be a more reliable parameter to predict transdermal absorption of nevirapine than flux.

\section{Keywords}

\section{Cosolvents, Surfactants, Partition Coefficient, Dermal Permeability Coefficient, Nevirapine}

\section{Introduction}

Nevirapine, chemically defined as 11-cyclopropyl-4-methyl-5,11-dihydro-6H-dipyrido $\left\{3,2-b: 2^{\prime}, 3^{\prime}\right.$-e $\}\{1,4\}$ diazepine-6-one has chemical structure presented in Figure 1.

Nevirapine is a non-nucleoside reverse transcriptase inhibitor (NNRTI) used clinically to treat HIV-1 infection. Its mechanism of action involves direct binding to reverse transcriptase (RT) thereby blocking the RNAdependent and DNA-dependent DNA polymerase activities resulting in the disruption of the enzyme's catalytic site [1]. Despite its high bioavailability (about 90\%) following oral administration and high elimination half life (about $45 \mathrm{~h}$ ), other properties of the drug such as first pass metabolism, poor aqueous solubility, decrease bioavailability at higher doses (>50 mg) make the drug a good candidate for transdermal delivery.

This route of drug delivery is easy to use and noninvasive, increases patient compliance, increases therapeutic index with simultaneous decrease in side effects and provides steady plasma level [2]-[4]. The successful use of transdermal drug delivery has mostly depended on understanding the movement of drugs through the dermal barriers.

The skin is composed of two layers namely the epidermis (nonvascular layer of about $100 \mu \mathrm{m}$ thick) and the dermis (highly vascularized layer of about 500 to $3000 \mu \mathrm{m}$ thick). However, the layer reported [5] [6] to provide the major barrier to the absorption of chemical substances deposited on the skin surface into the systemic circulation is the stratum corneum (outermost layer of the epidermis, about 10 to $40 \mu \mathrm{m}$ thick). Diffusion coefficient (D) contained in both Fick's first and second laws are often difficult to assess, however, abbreviation of the second law has allowed the introduction of the permeability coefficient [7].

The permeability coefficient is the principal factor used to estimate movements of drugs through the skin [8]. In addition to logarithm partition coefficient and molecular weight model [9] in the determination of dermal permeability coefficient, other models such as artificial neural network analysis and multiple regression analysis that incorporated other molecular constitutional descriptors namely number of hydrogen bond acceptors (nON),

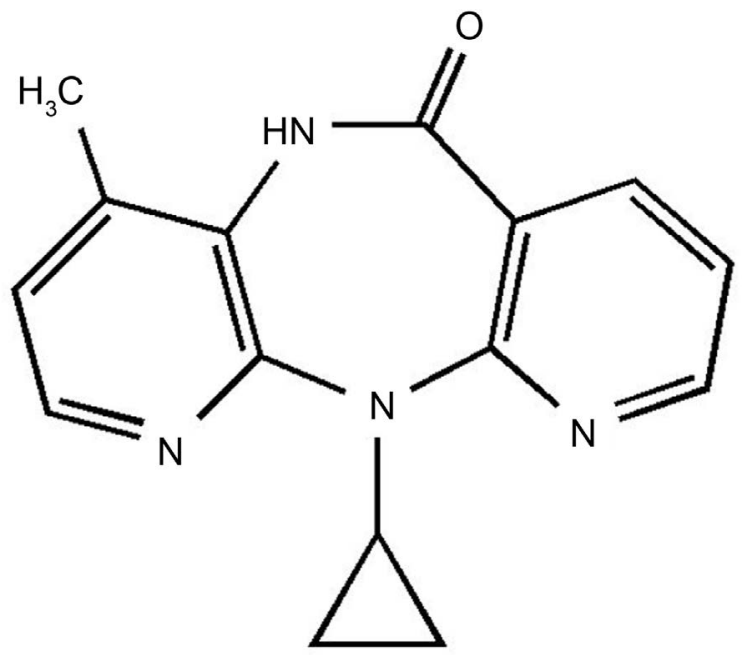

Figure 1. Chemical structure of nevirapime. 
number of hydrogen bond donors (nNHOH) and number of rotational bonds (nrotb), polar surface area etc. have also been used to determine dermal permeability coefficient. These additional models have shown that the application of more descriptors for dermal permeability coefficient determination increases the correlation coefficient $\left(\mathrm{r}^{2}\right)$ of determination.

Cosolvents and surfactants are often employed in cosmetic or pharmaceutical formulations to serve various purposes including percutaneous enhancement [10]-[12]. For instance, propylene glycol has been reported to enhance the skin permeability of estradiol [13], methotrexate [14] while polyethylene glycol 400 has been reported to be potential dermal absorption enhancer of benzophenone-3 [15]. Polysorbate surfactants have also been reported as dermal absorption enhancers [16].

In the present study, we investigate the effect of these vehicles on the partition coefficient of nevirapine while envisaging that the results of the study will provide some knowledge on the dermal enhancement potentials of the studied vehicles and invariably the dermal permeability coefficient of nevirapine. Potts and Guy [9] reported dermal permeability coefficient to depend on the partition coefficient and molecular weight of chemical compounds. In another report [17], partition coefficient has been shown to be used to evaluate dermal absorption of chemical compounds. Against this background as well as lack of previous report on this subject matter following literature review, we therefore report on the effect of cosolvents and surfactants on the partition coefficient of nevirapine.

\section{Materials and Methods}

Nevirapine (Boehringer Ingelhem, USA), glycerol, propylene glycol, polyethylene glycol 400, polysorbate 20 (tween 20), polysorbate-80 (tween 80), sodium lauryl sulfate, sodium cholate, cetrimide were purchased from Sigma-Aldrich (USA), chloroform was purchased from Fisher Scientific (USA) and other chemicals were of analytical reagent grade.

\subsection{Standard Solution}

Stock solution of nevirapine $(10 \mu \mathrm{g} / \mathrm{ml})$ was prepared in methanol. Aliquots $(1.0-5.0 \mu \mathrm{g} / \mathrm{ml})$ of the standard stock solution were pipetted into a $10 \mathrm{ml}$ volumetric flask diluted to volume with methanol.

\subsection{Partition Coefficient Measurement}

The partition coefficient of nevirapine was determined in a chloroform-water system. To 5 ml of chloroform (saturated with different vehicles studied) containing $100 \mu \mathrm{g} / \mathrm{m}$ of nevirapine was added $5 \mathrm{ml}$ of aqueous solution (saturated with chloroform) of different concentrations of glycerol, propylene glycol, ethanol, polyethylene glycol 400, polysorbate-20, polysorbate-80, sodium lauryl sulfate, sodium cholate and cetrimide. The vials were capped and agitated at room temperature for $2 \mathrm{~h}$ to achieve complete equilibration. The aqueous phase was analyzed using UV/Vis spectrophotometer at a maximum wavelength of $275 \mathrm{~nm}$. The drug concentration in the aqueous layer was obtained from the calibration graph. The partition coefficient of nevirapine was calculated using this equation [18]:

$$
P=\frac{\left(C_{1}-C_{w}\right) V_{w}}{C_{w} V_{o}}
$$

where $P=$ partition coefficient; $C_{1}=$ total concentration of gemifloxacin; $C_{w}=$ concentration of gemifloxacin in aqueous phase; $V_{w}=$ volume of the aqueous phase; $V_{o}=$ volume of the organic phase.

The determination was carried out in triplicates.

\section{Results and Discussion}

The results of the present study are presented in Tables 1-3 respectively. In Table 1 , the results show that the effect of glycerol, propylene glycol, ethanol and polyethylene glycol 400 on the partition coefficient of nevirapine. It was observed that all the cosolvents decreased the partition coefficient of the drug. The decrease was observed as the concentration of each cosolvent increases. Polyethylene glycol 400 gave the highest decreasing effect on the partition coefficient of the drug. For example, at the highest concentration investigated (25\% w/v), the logarithm partition coefficients of nevirapine are 2.1944, 1.9941, 1.3671 and 0.9841 for glycerol, propylene 
Table 1. Effect of glycerol, propylene glycol, ethanol and polyethylene glycol 400 on the partition coefficient of nevirapine and estimated permeability coefficients.

\begin{tabular}{ccccccccc}
\hline \multirow{2}{*}{$\begin{array}{c}\text { Conc } \\
(\% \mathrm{w} / \mathrm{v})\end{array}$} & \multicolumn{3}{c}{ Log Partition Coefficient (mean $\pm \mathrm{SD})$} & \multicolumn{2}{c}{ Log Dermal Permeability Coefficient } \\
\cline { 2 - 10 } & Glycerol & $\begin{array}{c}\text { Propylene } \\
\text { glycol }\end{array}$ & Ethanol & $\begin{array}{c}\text { Polyethylene } \\
\text { glycol } 400\end{array}$ & Glycerol & $\begin{array}{c}\text { Propylene } \\
\text { glycol }\end{array}$ & $\begin{array}{c}\text { Ethanol } \\
\text { Polyethylene } \\
\text { glycol 400 }\end{array}$ \\
\hline 0.0 & $2.7680 \pm 0.036$ & $2.768 \pm 0.036$ & $2.768 \pm 0.036$ & $2.768 \pm 0.036$ & -2.379 & -2.379 & -2.379 & -2.379 \\
5.0 & $2.5709 \pm 0.041$ & $2.5327 \pm 0.016$ & $2.3712 \pm 0.048$ & $1.9977 \pm 0.038$ & -2.5191 & -2.5462 & -2.6609 & -2.9261 \\
10.0 & $2.5234 \pm 0.007$ & $2.4627 \pm 0.031$ & $2.2325 \pm 0.026$ & $1.5629 \pm 0.029$ & -2.5528 & -2.5959 & -2.7594 & -3.2348 \\
15.0 & $2.4707 \pm 0.011$ & $2.0623 \pm 0.025$ & $1.9499 \pm 0.021$ & $1.4026 \pm 0.002$ & -2.5902 & -2.8802 & -2.9600 & -3.3486 \\
20.0 & $2.3368 \pm 0.063$ & $2.0414 \pm 0.021$ & $1.7043 \pm 0.008$ & $1.2004 \pm 0.006$ & -2.6853 & -2.8950 & -3.1344 & -3.4921 \\
25.0 & $2.1944 \pm 0.056$ & $1.9941 \pm 0.013$ & $1.3671 \pm 0.029$ & $0.9841 \pm 0.015$ & -2.7864 & -2.9286 & -3.3738 & -3.6457 \\
\hline
\end{tabular}

$\mathrm{SD}=$ standard deviation

Table 2. Effect of tween 20, tween 80, sodium lauryl sulfate, sodium cholate and cetrimide on the partition coefficient of nevirapine and estimated permeability coefficients.

\begin{tabular}{|c|c|c|c|c|c|c|c|c|c|c|}
\hline \multirow[b]{2}{*}{$\begin{array}{l}\text { Conc } \\
(\% \mathrm{w} / \mathrm{v})\end{array}$} & \multicolumn{5}{|c|}{$\log$ Partition Coefficient (mean $\pm \mathrm{SD}^{*}$ ) } & \multicolumn{5}{|c|}{ log Dermal Permeability Coefficient } \\
\hline & $\begin{array}{c}\text { Tween } \\
20\end{array}$ & $\begin{array}{c}\text { Tween } \\
80\end{array}$ & $\begin{array}{l}\text { Sodium } \\
\text { lauryl } \\
\text { sulfate }\end{array}$ & $\begin{array}{l}\text { Sodium } \\
\text { cholate }\end{array}$ & Cetrimide & $\begin{array}{c}\text { Tween } \\
20\end{array}$ & $\begin{array}{l}\text { Tween } \\
20\end{array}$ & $\begin{array}{c}\text { Sodium } \\
\text { lauryl } \\
\text { sulfate }\end{array}$ & $\begin{array}{l}\text { Sodium } \\
\text { cholate }\end{array}$ & Cetrimide \\
\hline 0.0 & 2.7680 & 2.7680 & 2.7680 & 2.7680 & 2.7680 & -2.3790 & -2.3790 & 2.7680 & -2.3790 & -2.3790 \\
\hline 0.05 & 2.2270 & 2.1999 & 2.3169 & 2.1536 & 1.9292 & -2.7633 & -2.7825 & -2.6994 & -2.8154 & -2.9747 \\
\hline 0.10 & 2.2158 & 2.1840 & 1.9056 & 1.9499 & 1.6450 & -2.7712 & -2.7938 & -2.9915 & -2.9600 & -3.1765 \\
\hline 0.20 & 2.0665 & 1.8701 & 1.8080 & 1.8283 & 1.4814 & -2.8772 & -3.0167 & -3.0463 & -3.0463 & -3.2926 \\
\hline 0.50 & 1.7364 & 1.6427 & 1.5864 & 1.5534 & 1.2144 & -3.1116 & -3.1781 & -3.2181 & -3.2415 & -3.4822 \\
\hline 1.00 & 1.6538 & 1.5515 & 1.4713 & 1.3528 & 1.0522 & -3.1702 & -3.2429 & -3.2998 & -3.3839 & -3.5974 \\
\hline 2.00 & 1.5384 & 1.3966 & 1.2700 & 1.2465 & 0.9141 & -3.2522 & -3.3528 & -3.4427 & -3.4594 & -3.6954 \\
\hline
\end{tabular}

$\mathrm{SD}^{*}=$ standard deviation range: $0.002-0.067$.

Table 3. Predicted maximum flux of nevirapine from predicted permeability coefficient and drug aqueous solubility.

\begin{tabular}{|c|c|c|c|c|c|c|c|c|}
\hline \multirow[b]{2}{*}{$\begin{array}{l}\text { Conc } \\
(\% \mathrm{w} / \mathrm{v})\end{array}$} & \multicolumn{3}{|c|}{ Flux $\left(\mu \mathrm{g} / \mathrm{cm}^{2} / \mathrm{h}\right)$} & \multirow[b]{2}{*}{$\begin{array}{l}\text { Conc } \\
(\% \mathrm{w} / \mathrm{v})\end{array}$} & \multicolumn{4}{|c|}{ Flux $\left(\mu \mathrm{g} / \mathrm{cm}^{2} / \mathrm{h}\right)$} \\
\hline & Glycerol & $\begin{array}{c}\text { Propylene } \\
\text { glycol }\end{array}$ & $\begin{array}{l}\text { Polyethylene } \\
\text { glycol } 400\end{array}$ & & Tween 20 & Tween 80 & $\begin{array}{l}\text { Sodium } \\
\text { lauryl } \\
\text { sulfate }\end{array}$ & Cetrimide \\
\hline 0.0 & 0.3282 & 0.3282 & 0.3282 & 0.0 & 0.3282 & 0.3282 & 0.3282 & 0.3282 \\
\hline 5.0 & 0.4423 & 0.5318 & 0.4581 & 0.05 & 0.2902 & 0.3553 & 0.3636 & 0.1960 \\
\hline 10.0 & 0.5582 & 0.9604 & 0.2477 & 0.10 & 0.3707 & 0.4160 & 0.3027 & 0.0893 \\
\hline 15.0 & 0.8489 & 0.6697 & 0.3184 & 0.20 & 0.3265 & 0.2855 & 0.3993 & 0.1088 \\
\hline 20.0 & 0.9719 & 1.0179 & 0.5690 & 0.50 & 0.3108 & 0.3305 & 0.3938 & 0.0970 \\
\hline 25.0 & 1.1276 & 1.6084 & 0.6847 & 1.00 & 0.4387 & 0.4435 & 0.5132 & 0.1111 \\
\hline & & & & 2.00 & 0.6850 & 0.6418 & 0.7040 & 0.1721 \\
\hline
\end{tabular}

glycol, ethanol and polyethylene glycol 400 respectively. The results might be explained if we assume that the squeezing out of the drug from the aqueous phase decreased as the polarity of the vehicles decreases thereby resulting in the drug partitioning less into the organic phase. Table 1 also contains the results of the predicted permeability coefficient of the drug as influenced by the cosolvents. The results suggest that hydration of the rat 
skin could be part of skin permeation

Previous report has shown diffusion coefficients of alcohols in hydrated skin were ten times that observed in dry skin [19].

Figure 2 shows a plot of concentration of cosolvent versus logarithm of partition coefficient. In Figure 2, a close linear relationship was observed with correlation coefficients of $-0.9801,-0.9134,-0.9887$ and -0.9016 for glycerol, propylene glycol, ethanol and polyethylene glycol 400 respectively.

The results in Table 2 show the effect of surfactants on the partition coefficient of nevirapine. The data indicate that all the surfactants also decreased the partition coefficient of the drug. Cetrimide was found to produce the highest decreasing effect on the partition coefficient of nevirapine. The decrease in the partition coefficient of the drug observed with tween 20 and tween 80 might be due to the drug entrapment in the micelles thus limiting the partitioning of the drug from the aqueous phase into the organic phase. This hypothesis seemed to be substantiated when it was observed that tween 80 which has longer alkyl chains than tween 20 produced lower partition coefficient when compared to tween 20. The effect observed with the cetrimide might be due ion pair formation that significantly limited the partitioning of the drug into the organic phase. With sodium lauryl sulfate, both micellar entrapment and ionization (pH effect) would account for its effect on the partition coefficient of the drug (acidic). The ionization effect seemed to have more effect with sodium cholate than sodium lauryl sulfate.

However, the surfactants gave less linear relationship with correlation coefficients of $-0.7885,-0.7780$, $-0.7772,-0.7713$ and -0.7257 for tween 20 , tween 80 , sodium cholate, sodium lauryl sulfate and cetrimide respectively. Plot of concentration of surfactant versus logarithm of partition coefficient is not shown due to lack of uniformity in point scattering. The experimental logarithm partition coefficient values were utilized to predict the dermal permeability coefficient of nevirapine through the skin. This was accomplished by the application of Potts and Guy equation:

$$
\log K p(\mathrm{~cm} / \mathrm{h})=-2.72+0.71(\log P)-0.0061(\mathrm{MW}),
$$

where $K p$ is the dermal permeability coefficient, $P$ is the partition coefficient and MW is the molecular weight of nevirapine respectively. Permeability coefficient has been reported to be a useful parameter in evaluating dermal absorption of drugs and has produced effective results [20] [21]. The product of predicted permeability coefficient and the drug aqueous solubility provides the maximum predicted flux through skin. The results are presented in Table 3.

In an effort to ascertain which of the two parameters namely permeability coefficient and flux would be the better parameter to describe the potential dermal absorption of nevirapine, we chose polyethylene glycol 400 and sodium lauryl sulfate at their different concentration levels. These vehicles were found in the previous report [22] to produce the highest aqueous solubility of nevirapine at the maximum concentration investigated. With polyethylene glycol 400, a plot of predicted permeability coefficient of nevirapine against log partition coefficient gave correlation coefficient $\left(r^{2}\right)$ of 0.9699 whereas a correlation coefficient $\left(r^{2}\right)$ of -0.5399 was obtained

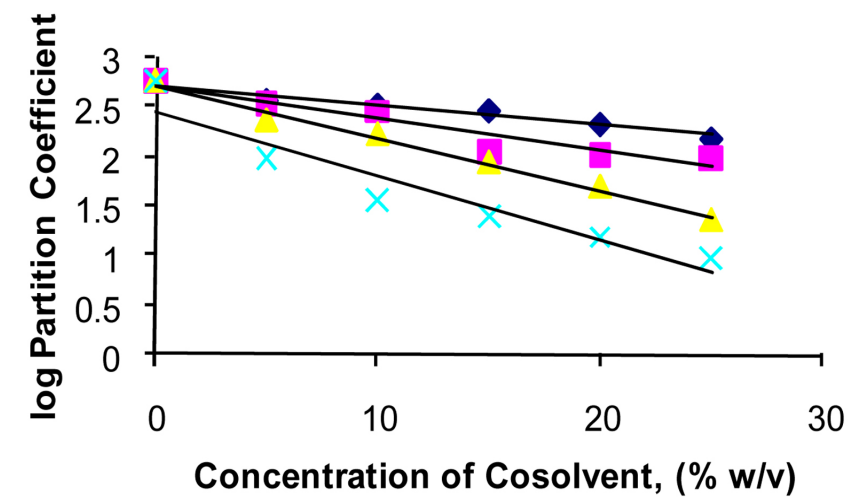

Figure 2. Plot of logarithm partition coefficient versus concentration of cosolvent, $\square-------\square$ Glycerol, $\square-------\square$ Propylene glycol, $\Delta$----- $\Delta$ Ethanol, $\times------\times$ Polyethylene glycol 400. 
when the maximum predicted flux was plotted against logarithm partition coefficient. A similar plot with the results of sodium lauryl sulfate gave correlation coefficients $\left(\mathrm{r}^{2}\right)$ of 0.9473 and -0.7219 for predicted permeability coefficient and maximum predicted flux respectively. An increase in correlation coefficient $\left(\mathrm{r}^{2}\right)$ indicates an improved fit of the raw data and substantiates the accuracy of that model in the prediction of dermal permeability coefficient. The results of the correlation coefficients therefore suggest that permeability coefficient could be a more reliable parameter than flux in describing the percutaneous absorption of nevirapine.

\section{Conclusion}

Amongst the cosolvents studied, polyethylene glycol 400 showed the highest decreasing effect on the partition coefficient of nevirapine. With the surfactants, the highest decrease was observed with cetrimide. The maximum predicted flux $\left(\mu \mathrm{g} / \mathrm{cm}^{2} / \mathrm{h}\right)$ was obtained from the product of predicted permeability coefficient and the drug aqueous solubility. The results of the correlation coefficients obtained by plotting predicted permeability coefficient or maximum predicted flux versus logarithm partition coefficient indicated that permeability coefficient could be a more reliable parameter than the flux in predicting transdermal absorption of nevirapine. Thus, if permeability coefficient is to be used to predict the transdermal absorption of nevirapine, the results then suggest that glycerol and polysorbate 20 when compared to other vehicles investigated, are potential transdermal absorption enhancers of nevirapine and hence the preferred vehicles to be employed in the formulation of topical pharmaceutical products containing nevirapine. The results also suggest that: 1) nevirapine can be formulated into a transdermal dosage form containing glycerol and/or tween 20 as potential dermal enhancers of the drug for the treatment of HIV patients; 2) pharmaceutically, nevirapine can be fabricated into a transdermal patch. Finally, based on the significance of the findings, future work shall involve both in vitro and in vivo investigations.

\section{References}

[1] Thomson, P.D.R. (2005) Physcian Desk Reference. 59th Edition, New Jersey.

[2] Bajaj, S., Whiteman, A. and Brandner, B. (2011) Pharmacokinetics of Transdermal drug Delivery. Disclosures Cont Edu Anaseth Crit Care and Pain, 11, 39-43.

[3] Paudal, K., Milewski, M., Swadley, C., Brogden, N., Ghosh, P. and Stinchcomb, A.L. (2010) Challenges and Opportunities in Dermal Transdermal Delivery. Therapeutic Delivery, 1, 109-131. http://dx.doi.org/10.4155/tde.10.16

[4] Kwatra, S., Taneja, G. and Nasa, N. ( 2012) Alternatives Routes of Drug Administration-Transdermal, Pulmonary and Parenteral. Indo Global Journal of Pharmaceutical Sciences, 2, 409-426.

[5] Ghosh, T.K. and Bonga, A.K. (1993) Methods of Enhancement of Transdermal Drug Delivery: Part I, Physical and Biochemical Approaches. Pharmaceutical Technology, 17, 72-132.

[6] Scheuplein, R.J. and Blank, I.H. (1971) Permeability of the Skin. Physiological Reviews, 51, 702-742.

[7] Steea-Knudsen, O. (2002) Biological Membrane: Theory of Transport, Potentials and Electric Impulses. Cambridge University Press, London.

[8] Rutter, N. (1987) Drug Absorption through the Skin: A Mixed blessing. Archives of Disease in Childhood, 62, $220-221$. http://dx.doi.org/10.1136/adc.62.3.220

[9] Potts, R.V. and Guy, R.H. (1992) Predicting Skin Permeability. Pharmaceutical Research, 9, 663-669. http://dx.doi.org/10.1023/A:1015810312465

[10] Shen, W.W., Danti, A.G. and Bruscato, F.N. (1976) Effect of Nonionic Surfactants on Percutaneous Absorption of Salicyclic Acid and Sodium Salicylate in the Presence of Dimethylsulfoxide. Journal of Pharmaceutical Sciences, 65, 1780-1783. http://dx.doi.org/10.1002/jps.2600651222

[11] Hwang, C.C. and Danti, A.G. (1983) Percutaneous Absorption of Flufenamic Acid in Rabbits. Effect of Dimethylsulfoxide and Various Nonionic Surface Active Agents. Journal of Pharmaceutical Sciences, 72, 857-860. http://dx.doi.org/10.1002/jps.2600720805

[12] Toniton, E. (1986) Transdermal Delivery of Anxiolytics. In Vitro Skin Permeation of Midazolam Maleate and Diazepam. International Journal of Pharmaceutics, 33, 37-43. http://dx.doi.org/10.1016/0378-5173(86)90036-0

[13] Mollsaard, B. and Hoelguard, A. (1983) Permeation of Estradiol through the Skin. Effect of Vehicles. International Journal of Pharmaceutics, 15, 185-197. http://dx.doi.org/10.1016/0378-5173(83)90142-4

[14] Vaigyanathan, R., Chaubai, M.G. and Vasavada, R.C. (1985) Effect of pH and Solubility on in Vitro Skin Permeation of Methotrexate from a 50\% v/v Propylene Glycol-Water Vehicles. International Journal of Pharmaceutics, 25, 85-93. 
http://dx.doi.org/10.1016/0378-5173(85)90106-1

[15] Mbah, C.J. (2007) The Effect of Glycerol, Propylene Glycol and Polyethylene Glycol 400 on the Partition Coefficient of Benzophonone-3 (Oxybenzone). Die Pharmazie, 62, 38-40.

[16] Akhtar, N., Rehman, M.U., Khan, H.M.S., Rasool, F., Saeed, T. and Murtaza, G. (2011) Penetration Enhancing Effect of Polysorbate 20 and 80 on the in Vitro Percutaneous Absorption of L-Ascorbic Acid. Tropical Journal of Pharmaceutical Research, 10, 281-288. http://dx.doi.org/10.4314/tjpr.v10i3.1

[17] Bunge, A.L. and Cleek, R.L. (1995) A New Method for Estimating Dermal Absorption from Chemical Exposure. Effect of Molecular Weight and Octanol-Water Partitioning. Pharmaceutical Research, 12, 88-95. http://dx.doi.org/10.1023/A:1016242821610

[18] Johansen, M. and Bundgaard, H. (1980) Prodrugs as Drug Delivery Systems XI. Solubility, Dissolution and Partition Behaviour of N-Mannich Bases and N-Hydroxymethyl Derivatives. Arch. Pharm. Chem. Sci. Edu., 8, 141-151.

[19] Roberts, M.S. and Walker, M. (1993) Penetration Enhancement by Stratum Corneum Modification. Pharmaceutical Skin Penetration Enhancement, Marcel Dekker, New York, 1-30.

[20] Karinth, S., Schaller, K.H. and Drexler, H. (2005) Is Permeability Coefficient Kp a Reliable Tool in Percutaneous Absorption Studies. Archives of Toxicology, 79, 155-159. http://dx.doi.org/10.1007/s00204-004-0618-4

[21] (1992) United States Environmental Protection Agency: Dermal Exposure Assessment: Principles and Applications. EPA/600/8-91/011 B.

[22] Mbah, C.J., Omeje, E.O. and Ugodi, G.W. (2016) Aqueous Solubility of Nevirapine: Enhancement by Cosolvency and Micellization. Brazilian Journal of Pharmaceutical Sciences, in press.

\section{Submit or recommend next manuscript to SCIRP and we will provide best service for you:}

Accepting pre-submission inquiries through Email, Facebook, LinkedIn, Twitter, etc.

A wide selection of journals (inclusive of 9 subjects, more than 200 journals)

Providing 24-hour high-quality service

User-friendly online submission system

Fair and swift peer-review system

Efficient typesetting and proofreading procedure

Display of the result of downloads and visits, as well as the number of cited articles

Maximum dissemination of your research work

Submit your manuscript at: http://papersubmission.scirp.org/ 